JIOM Nepal, Volume 41, Number 2, August 2019, page 67-69

\title{
Elderly Great Grand Multipara with Gestational Hypertension and Anemia Managed in a Rural Tertiary Hospital: A Case Report
}

\author{
Uma Shrestha \\ Karnali Academy of Health Sciences, Jumla, Nepal \\ Corresponding author: \\ Uma Shrestha, MSc Nursing \\ Karnali Academy of Health Sciences, Jumla, Nepal \\ Email:umaandson@gmail.com
}

Submitted: May 13, 2019

Accepted : Jul 27, 2019

\begin{abstract}
Introduction

Parity more than five is grand multiparity and more than 10 is great grand multiparity. Women with high birth order are at increased risk for adverse obstetric outcomes. The risk is even higher for great grand multiparous women than grand multiparous women. Grand and Great grand multiparity predispose for adverse maternal and perinatal outcomes such as malpresentation, labor dystocia, caesarean delivery, postpartum hemorrhage, maternal anemia, congenital malformations and perinatal mortality. Grand and Great grand multiparty is also independent risk factor for labor dystocia and perinatal mortality. However, most of the adverse outcomes that have been associated with grand multiparity may actually be confounded by advanced age, less antenatal care and low socioeconomic level. Although pregnancy hypertension is more commonly seen among young primigravidas, hypertension is equally common in elderly women. This is a unique case of elderly great grand multiparous women with moderate anemia who developed gestational hypertension and underwent emergency cesarean section resulting into normal maternal and fetal outcome.
\end{abstract}

Keywords: Elderly, gestational hypertension, great grand multiparity, pregnancy outcome

\section{INTRODUCTION}

Grand multiparty (GM) was introduced in medical literature in 1934 by Solomon and termed this condition as dangerous. ${ }^{1} \mathrm{GM}$ was previously defined as parity $>7$ but the International Federation of Gynecology and Obstetrics (FIGO) defines GM as five deliveries or more in view of marked increase in the risks of obstetric complications, neonatal morbidity, and perinatal death at parity $\geq 5 .^{2-5}$ When the parity is 10 or above, it's called great grand multiparity (GGM) which further increases the incidence of adverse maternal and neonatal outcome. There has been substantial difference in the prevalence of GM and GGM between western world and developing countries. Developed countries have a low prevalence of GM (3-4\% of all births) where as there is high prevalence of $\mathrm{GM}$ in developing countries. ${ }^{6-9}$ This difference is due to availability and access to contraceptives as well as antenatal care, adequate medical facilities and skilled health personals for safe delivery.

Several studies have provided data concerning the risk of great and grand multiparity for both mother and fetus. ${ }^{10-14}$ However, some studies show that grandmultiparity does not necessarily lead to significant additional maternal, fetal, or neonatal complications in developed world where there is availability of high quality healthcare services. ${ }^{13}$

Young privigravidas are at increased risk of developing pregnancy hypertension including gestational hypertension a well as preeclampsia in comparison whereas elderly and multigravidas are also equally at risk of developing hypertension.

\section{CASE PRESENTATION}

I hereby present a case of great grand multipara who presented to maternity unit of Karnali Academy of Health Sciences (KAHS) teaching hospital in May 2018.

Mrs. JD, 45 years old great grand multiparous woman (G21P15A5L9) was referred from a PHC of Kalikot District with the complaints of amenorrhea of 9 months and lower abdomen and back pain of 10 hours duration associated with difficulty in breathing and raised blood pressure of $160 / 110 \mathrm{mmHg}$. She said she is appreciating her fetal movement well. There was no history of vaginal bleeding or leaking 
of fluids. She had 3 Antenatal Clinic visits at PHC, took tetanus prophylaxis and was on regular iron supplements. There was no antennal Ultrasound and any other blood investigations done and there was no any record of high blood pressure before presentation to KAHS.

Her obstetrics history was G21P15A5L9, all previous deliveries were home delivery and she doesn't remember the exact chronology and events of all the deliveries. Five out of six abortions were induced and one was spontaneous miscarriage which happened during $4^{\text {th }}$ month of pregnancy long time back. Her past medical and surgical history was not significant. She was smoker but non-alcoholic. The couple was not under any contraception. She has history of amenorrhea of 2 years prior to present pregnancy which led them think that she was already menopausal.

On examination, she was thinly built, anxious and pale. There was no edema. Her blood pressure was $160 / 110 \mathrm{mmHg}$ on both the arms on sitting position and pulse was 92 beats per minute $(\mathrm{bpm})$ and regular. Examination of abdomen showed uterine size of around 34 weeks and it was cephalic presentation. Fetal heartbeat was 124 bpm.

Her blood investigations including liver function and renal function tests were normal and her hemoglobin was $8.4 \mathrm{gm} \%$. Obstetrics ultrasound showed single pregnancy of 33 weeks with estimated fetal weight of $2.4 \mathrm{~kg}$. Her blood pressure was monitored closely which was persistently high $>160 / 110 \mathrm{~mm}$ $\mathrm{Hg}$ in both the arms. Injection Dexamethasone 4 doses 12 hourly was given to enhance fetal lung maturity and antihypertensive (Tab Nifedipine 10 mg TID) was started. She underwent emergency cesarean section and bilateral tubal ligation after 48 hours in view of persistent severe hypertension despite antihypertensive. The fetal weight was 2.3 $\mathrm{kg}$ and both mother and baby were discharged in good health. She received two pints of fresh blood transfusion postoperatively.

\section{DISCUSSION}

In general, great grand multiparity possesses a risk for both mother and fetus. Furthermore, high parity has been deemed a burden to the family and health systems. There have been many studies done in many countries to find out the occurrence, incidence and complications of grand and great grand multiparity. These studies have shown various results for and against the negative maternal and fetal outcome of grand multiparity. A study done in Tanzania shows that GM remains a risk in pregnancy and is associated with an increased prevalence of maternal and neonatal complications (malpresentation, meconiumstained liquor, placenta previa and a low Apgar score) as compared with other multiparous women. ${ }^{15}$
Another study done in Croatia showed that although labor complications were similar between multipara and grand multi para, the cesarean delivery rate was significantly higher in $\mathrm{GM} .{ }^{16}$ Likewise, mean duration of labor was similar between the two groups, but prolonged labor of more than 24 hours was more frequent among GM and mean birth weight was significantly lower for neonates born to grand multiparous women.

Another study done in France shows that grand multiparas were more likely to have had little or no education (none or grade school level), to be smokers, to have an increased body mass index, and to have had poorer prenatal care. ${ }^{17}$ There was a tendency to an increased rate of gestational hypertension, although the incidence of preeclampsia and chronic hypertension. They had greater previous histories of fetal or perinatal deaths and had also sought more abortions which is very similar in this case.

This case represents a very unique scenario of the maternal, child health and family planning $(\mathrm{MCH} /$ FP) situation of Karnali province of Nepal, which is very rural, remote and backward in various aspects. Complications and consequences of repeated pregnancies in this case like anemia, transfusion related complications, unnecessary operations could have been easily avoided.

Lack of proper education as well as information on advantages and availability of contraceptive methods is still one of the major problem in rural Nepal. Unmet need of family planning is still very high. This ignorance has added huge psychological, physical as well as economic burden in women's life, family and ultimately to the society.

\section{CONFLICT OF INTEREST}

None declared.

\section{REFERENCES}

1. Lyrenas S: Labor in the grand multipara. Gynecol Obstet Invest 2002, 53(1):6-12.

2. Fuchs $K$, Peretz B-A, Marcovici R, Paldi E, Timor-Tritsh I: The "Grand Multipara" — Is it a problem? A review of 5785 cases. Int J Gynecol Obstet 1985, 23(4):321-326.

3. Toohey JS, Keegan KA Jr, Morgan MA, Francis J, Task $\mathrm{S}$, de Veciana M: The "dangerous multipara": fact or fiction? Am J Obstet Gynecol 1995, 172(2 Pt 1):683-686.

4. Babinszki A, Kerenyi T, Torok O, Grazi V, Lapinski RH, Berkowitz RL: Perinatal outcome in grand and greatgrand multiparity: effects of parity on. Am J Obstet Gynecol 1999, 181(3):669-674.

5. Simonsen SM, Lyon JL, Alder SC, Varner MW: Effect of grand multiparity on intrapartum and newborn complications in young. Obstet Gynecol 2005, 106(3):454-460.

6. WHO: WHO Report. Geneva: WHO; 2004. Available from: http://www.who.int/ whr/2004/annex/country/can/en/.

7. Odukogbe AA, Adewole IF, Ojengbede OA, Olayemi O, 
Fawole BO, Ahmed Y, et al: Grandmultiparity-trends and complications: a study in two hospital settings. J Obstet Gynaecol 2001, 21(4):361-367.

8. Aziz-Karim S, Memon AM, Qadri N: Grandmultiparity: a continuing problem in developing countries. Asia Oceania J Obstet Gynaecol 1989, 15(2):155-160.

9. Rayamajhi $R$, Thapa M, Pande S: The challenge of grandmultiparity in obstetric practice. Kathmandu Univ Med J (KUMJ) 2006, 4(1):70-74.

10. Babinski A, Kerenyi $T$, Torok $O$, Grazi $V_{\text {, Lapinski } R H}$, Berkowitz RL. Perinatal outcomeingrand and greatgrand multiparity: effects of parity on obstetric risk factors. Am J Obstet Gynecol 1999;181:669-74.

11. Juntunen K, Kirkinen P, Kauppila A. The clinical outcome in pregnancies of grand grand multiparous women. Acta Obstet Gynecol Scand 1997;76(8):755-9.

12. Fuchs K, Peretz BA, Marcovici R, Paldi E, Timor-Tritsch I. The "grand multipara"-is it a problem? A review of 5785 cases. Int J Gynecol Obstet 1985;23(4):321-6.

13. Seidman DS, Dollberg S, Stevenson DK, Gale R. The effects of high parity and socioeconomic status on obstetric and neonatal outcome. Arch Gynecol Obstet 1991;249(3):119-27.

14. 14.Bai J,Wong FW, Bauman A, Mohsin M: Parity and pregnancy outcomes. Am J Obstet Gynecol $2002 ; 186(2): 274-8$.

15. Mgaya et al: Grand multiparity: is it still a risk in pregnancy? BMC- Pregnancy and Childbirth 2013, 13:241

16. Severinski N S, Mamula O, Severinski S, Mamula MMaternal and fetal outcomes in grand multiparous women. International Federation of Gynecology and Obstetrics 2009. Published by Elsevier Ireland Ltd.

17. Roman et al: Outcomes in Grand Multiparity VOL. 103, NO. 6, JUNE 20042004 by The American College of Obstetricians and Gynecologists 